\title{
Integrated models in psychiatry: the state of the art
}

\author{
Ulrich Reininghaus $\cdot$ Craig Morgan
}

Received: 18 November 2013/ Accepted: 26 November 2013/Published online: 4 December 2013

(C) Springer-Verlag Berlin Heidelberg 2013

Social psychiatry has now been a part of psychiatry as a scientific discipline for a century, since Ilberg [1] and Southard [2] first used the term. The remit of social psychiatry is broad, ranging from investigations of social factors in the aetiology of mental disorders, to community psychiatry and health services research, to global and public mental health. However, given psychiatry's primary orientation to the medical and biological, social psychiatry has held a rather tenuous position, perhaps even more so now, since rapid advances in genetics and neuroscience promise to unearth the basic biological underpinnings of mental disorders. However, intriguingly these advances have demonstrated social psychiatry is central to understanding mental disorders more fully, in all its facets [3]. Indeed, through recent research on genetics and neurobiology, it has become increasingly clear that the social combines with, and impacts on, the biological and the psychological, in a multitude of ways, to increase risk for mental disorders.

The idea of such integrated models of mental disorder is not new. For instance, more than 30 years ago, George Engel [4] discussed the clinical application of a biopsychosocial model and, more recently, Kenneth Kendler [5, 6] put forward strong philosophical arguments for what he coined 'pluralistic explanatory models'. Recently, research on integrated models of mental disorder has gained momentum and, while still limited in extent, we have never been as close to generating robust evidence on the interplay

\footnotetext{
U. Reininghaus $(\varangle) \cdot$ C. Morgan

Section of Social Psychiatry, Health Service and Population

Research Department, NIHR Biomedical Research Centre,

Centre for Epidemiology and Public Health, Institute of

Psychiatry, King's College London, London, UK

e-mail: ulrich.reininghaus@kcl.ac.uk
}

of the social, psychological, and biological. One prominent example of this is research on gene-environment interactions in common mental disorders and (to a lesser degree) in schizophrenia and other psychoses [7-10]. Recent advances in epigenetic profiling, for example, allow us now to investigate the impact of environmental exposures on gene expression to increase the risk of mental disorder [11]. Further, the current upsurge in social neuroscience has generated (initial) insights into neural mechanisms through which environmental exposures may impact on the development of mental disorders [12]. There is also an emerging evidence on neuroendocrine and inflammatory mechanisms that may link childhood adversity and risk of mental disorders, including psychoses [13]. Finally, recent advances in clinical psychology further suggest that repeated exposure to social adversity can link to mental disorder (including more severe forms such as psychosis) through specific cognitive and affective mechanisms (e.g. social cognitive biases, stress sensitivity, disturbances in affect, etc.).

This is not to imply that the social does not warrant investigation in its own right. Mental disorders are intrinsically social. They are shaped by, and in turn shape, social contexts and experiences. However, in abandoning the (presumed) polarities between the social, psychological and biological, and embracing an evidence-based approach for identifying biological and psychological mechanisms, integrated investigations of mental disorders add (even) more weight to the social as a (potential) contributory cause of the onset and outcomes of mental disorders. This, in turn, poses methodological challenges both in terms of optimising measurement of the social and in applying (and developing) novel epidemiological methods that allow us to test how specific social contexts and experiences combine, in multiple ways, with specific psychological and biological mechanisms in the origins of mental disorders. 
The current resurgence of social psychiatry in investigations of the causes of mental disorder reinvigorates the need for responding effectively and humanely to these in treatment and prevention. However, to date, treatment and prevention strategies that are effective in targeting the social, biological, and psychological remain rare (if nonexistent). Findings on the effectiveness of such strategies would further contribute to strengthening the evidence base in support of integrated models on social, biological, and psychological causes of mental disorders. What further complicates our strivings to understand mental disorders more fully is that most research originates from highincome countries, with the potential for distorting evidence on the aetiology of, and treatment for, mental disorders. The growth of the movement for global mental health currently seeks to address this issue.

As of this issue, Social Psychiatry and Psychiatric Epidemiology will publish a series of state-of-the-art reviews that aim to address (some of) these recent developments in social psychiatry and psychiatric epidemiology. The series will set off with invited reviews by researchers at the forefront of research at the interface between the social, psychological and biological. As part of this, in the current issues of Social Psychiatry and Psychiatric Epidemiology, Rudolf Uher reviews a decade of research into the explanatory potential of interplay between genetic and environmental factors in the development of common mental disorders. This will be followed in subsequent issues by reviews of gene-environment interactions in psychosis, epigenetic, neural and inflammatory mechanisms of environmental factors in the development of mental disorders, and the interface of physical and mental health. The series will then move on to address current challenges in the movement for global mental health, the development and application of epidemiological methods, and the development and evaluation of complex social interventions and systems of service delivery. In synthesising evidence on these and other key topics, the broader goal of the series is to provide a vibrant platform for reporting the state of the art in, and, ultimately, advancing research on, social psychiatry and psychiatric epidemiology.

Acknowledgments U.R. is supported by funding from a Postdoctoral Research Fellowship of the National Institute of Health
Research, UK. The report is independent research and the views expressed in this publication are those of the authors and not necessarily those of the NHS, the National Institute for Health Research or the Department of Health. C.M. is supported by funding from the Wellcome Trust (Grant Number: WT087417) and European Union (European Community's Seventh Framework Program (grant agreement No. HEALTH-F2-2009-241909) (Project EU-GEI)).

Conflict of interest None.

\section{References}

1. Ilberg G (1904) Soziale Psychiatrie. Monatszeitschr Soz Med 1:321-398

2. Southard EE (1917) Alienists and psychiatrists. Ment Hyg 1:567-571

3. Bhugra D, Morgan C (2010) Social psychiatry: alive and kicking. In: Morgan C, Bhugra D (eds) Principles of social psychiatry. Wiley, West Sussex

4. Engel G (1980) The clinical application of the biopsychosocial model. Am J Psychiatry 137:535-544

5. Kendler K (2001) A psychiatric dialogue on the mind-body problem. Am J Psychiatry 158:989-1000

6. Kendler K (2005) Toward a philosophical structure for psychiatry. Am J Psychiatry 162:433-440

7. Uher R (2008) The implications of gene-environment interactions in depression: will cause inform cure? Mol Psychiatry 13: 1070-1078

8. Caspi A, Sugden K, Moffitt T, Taylor A, Craig I, Harrington H, McClay J, Mill J, Martin J, Braithwaite A, Poulton R (2003) Influence of life stress on depression: moderation by a polymorphism in the 5-HTT gene. Science 301:386-389

9. Kendler KS, Kessler RC, Walters EE, MacLean C, Neale MC, Heath AC, Eaves LJ (1995) Stressful life events, genetic liability, and onset of an episode of major depression in women. Am J Psychiatry 152:833-842

10. Os Van, Rutten B, Poulton R (2008) Gene-environment interactions in schizophrenia: review of epidemiological findings and future directions. Schizophr Bull 34:1066-1082

11. Rutten B, Mill J (2009) Epigenetic mediation of environmental influences in major psychotic disorders. Schizophr Bull 35: $1045-1056$

12. Meyer-Lindenberg A, Tost H (2012) Neural mechanisms of social risk for psychiatric disorders. Nature 15:663-668

13. Mondelli V, Cattaneo A, Belvederi Murri M, Di Forti M, Handley R, Hepgul N, Miorelli A, Navari S, Papadopoulos A, Aitchison K, Morgan C, Murray R, Dazzan P, Pariante C (2011) Stress and inflammation reduce brain-derived neurotrophic factor expression in first-episode psychosis: a pathway to smaller hippocampal volume. J Clin Psychiatry 72:1677-1684 